\title{
Ethics and Learning
}

\author{
From State Regulation towards Reflexive Self-Regulation of \\ the Information Society \\ Tom Dedeurwaerdere*
}

Centre for Philosophy of Law, Université Catholique de Louvain, Place Montesquieu 2, 1348

\begin{abstract}
In this presentation we consider an original institutional solution proposed by E. Brousseau, for a hierarchical framing of the self-regulation of the Internet, which tries to encounter the incompleteness of solely technical means of selfregulation (standardisation or juridical selfrule) as well as the inefficiency of co-regulation in a classical sense. We evaluate this type of solution, both form the point of view of its contribution to a process of ethical learning and from the point of view of practical experiences from institutions for technology assessment and Internet regulation bodies such as ICANN.
\end{abstract}

Keywords: Internet, Information Society Governance, Procedural Ethics

*This research is part of a broader program on democratic governance developed at the Centre for Philosophy of Law (UCL, Belgium). An overview of its basic orientation can be found on the website of the Centre and, in particular, in its research report Theory of the Norm and Democratic regulation (http://www.cpdr.ucl.ac.be/en/e_rapports.html). Part of the research results presented here has also been the object of a Working Paper of the Centre (Dedeurwaerdere and Maesschalck [12]; http://www.cpdr.ucl.ac.be/en/e_publications.html). The author would like to thank Marc Maesschalck and Jacques Berleur for comments on earlier drafts of this paper.

The original version of this chapter was revised: The copyright line was incorrect. This has been corrected. The Erratum to this chapter is available at DOI: 10.1007/978-0-387-35609-9_29 


\section{INTRODUCTION}

The object of this presentation is an interrogation on the possible contribution of ethical reflection to an amelioration of the regulatory structures of the Internet. The starting point of our reflection is a diagnosis of the insufficiency of formal deontological ethical models in the actual discussions on the problem of regulation. These models remain on an abstract level and do not integrate their possible contribution to a better construction of the social efficiency of the reflexive judgements on actual regulation means (Kling [17] ; Berleur [5]). In order to go beyond this insufficiency, we will try to take into account recent developments within contemporary ethics - whether it be procedural (Sunstein [34] ; Habermas [13] ; Berleur [6]) or pragmatist ethics (Rorty [31]) - which emphasize the importance of contextual conditions of elaboration of norms in public space, in order to translate concretely the evolution towards a universal moral viewpointı.

From this point of view, what is important in the practical acceptance of a principle of action, is not so much its semantic justification but its submission to procedural agreements that guarantee the equity of viewpoints and roles in practical discussion. In that sense we will consider the institutional proposition of Eric Brousseau, which tries to go beyond the insufficiencies of a formal understanding of the co-regulation of the Internet, through institutional mechanisms acting on the evolution of normative orientations of the actors. This institutional or hierarchical framing aims at subordinating the existing contextual production of norms to a practical discussion through a set of procedural arrangements.

Even though a purely juridical interpretation of this proposition is possible (i.e. as a mechanism to introduce collective norms through institutional enforcement), we would like to evaluate its possible contribution to a process of ethical learning. From that point of view, the accent will be on the reflexive role of the institutional framing, as a second order mechanism acting on the evolution of the first order normative orientations of the actors and institutions. This concept of reflexivity is an

1 Through this general background of our research, we share the methodology used in Ethics and Governance of the Internet of the Special Interest Group on Ethics of the IFIP (Berleur, Duqenoy and Whitehouse [7] ; Berleur [5], p. 14) ; cf. also the remarks of J. Berleur on this methodology : "Finally, it is rather evident that self-regulation, in the sense in which we have used it, will not be very efficient if it is not supported by the will of an ethical behaviour of the users. It is not sufficient, however, to simply rely on their goodwill or their own convictions. The diversity of ethical norms, within the cultural horizon of the Internet, demands that procedures are put in place, so that through "discussion" some principles accepted by all can emerge" (Berleur [5], p. 20). 
extension to the field of the Internet of the concept used by Ulrich Beck in his analysis of the reflexive evolution of technical modernisation. In this sense, "reflexive" does not only mean the way the context of an activity (mental or physical) has an effect in return on this same activity, but also, as it is the case with U. Beck's concept of "reflexive modernisation", the way in which this "reflexive feedback" can cause a reconfiguration of the normative orientations that guide the actors and institutions (Beck [3], pp. 11-19). Our hypothesis is that such a reflexive interpretation is able to go beyond certain insufficiencies of the recourse to reflexivity in current propositions to ameliorate the regulation of the Internet.

\section{PROCEDURAL ETHICS AND REFLEXIVITY OF THE SOCIO-TECHNICAL SYSTEMS}

First of all, we want to situate the debate on the regulation of the Information Society within the larger context of theories on means to regulate the revolution of socio-technical systems. Thus we want to take into account recent evolutions within procedural ethics, which consider the formal equity of viewpoints and roles in terms of their particular embedding in particular contexts (Maesschalck [24] ; Dedeurwaerdere [11]).

Currently, there are two basic currents, within theories about the regulation of the evolution of contemporary technology, that try to translate a condition of increasing reflexivity into the discussion procedures on common norms. The first consists of favouring the multiplication of different forms of reflexivity of the actors, in relation to the production of non intended side -effects of technological modernization (Beck [2]). Thus one aims to ameliorate the chances of success of actors who chose a cooperative strategy in response to the social effects and risks of the technological system, through a joint action on strategies of enrolling in the new actor networks and on its mode of organisation (Latour [18], pp. 250-251).

In the domain of the Internet, the actors of technical standardization are involved in such a joint action, combining a purely technical intervention with strategies of social integration and acceptance of the technical means proposed, through their influence on the issues of privacy protection, of the regulation of the content on the Internet or on the issue of intellectual property rights (Reidenberg [29], p. 554). As examples of such of joint action, we can cite the discussions concerning the IPIC norm (Platform for Internet Content Selection) for the selection of contents on the Internet (Berleur et Poullet [8], p. 3) and the controversy about the new Internet 
transmission protocol Ipv6, which requires a numerical identifier for each individual user (Reidenberg [29], p. 3). These examples cannot be reduced to purely technical discussions. They have to be situated in the larger context of a collective evolution towards a new phase of rationalisation of social relations, which combine technical knowledge and reflexivity on strategies of social embedding of technology. A similar evolution can be observed on the level of economic self-regulation, through the development of multiple local experimentations that try to integrate the reflexivity of the users. In a similar manner to the evolution of rules for technical standardisation, the development of tools of economic self-regulation - such as the introduction of labels for websites (Poullet [28], p. 75), the classification of computer games for young users (Reidenberg [29], p. 581) or the contractualisation of the relations between Internet users and providers containing a respect of an ethical code (Poullet [28], p. 59) - are not inspired by commercial interests alone, but have to be situated within the context of an evolution towards a more reflexive construction of the information society (Benkler [4], p. 562).

However, as one can also notice in other important domains of evolution of our governance structures (Maesschalck [21] et [23] ; Lenoble et Messchalck [19] ; Dedeurwaerdere [10]), this first form of gain in reflexivity remains inufficient. First of all, the increase in reflexivity of technical and economical actors often has a local character (Reidenberg [29], p. 583). Moreover, it does not look for other means of institutionalization than those including formal guarantees of transparency and flexibility of the selfregulated networks in order to achieve the possibility of new experimentations (Vivant [38] ; Sabel [33], p. 75 ; Verbiest and Wéry [37], p. 523). As such this first way does not develop any reflexivity on the sustainable integration of those experiments into visible engagements towards the future, giving concrete guarantees of a multiplication of spaces of reversible interaction between economical and technical subsystems on the one hand and social subsystems on the other.

The second way to translate the condition of increasing reflexivity tries to go beyond this insufficiency through a mechanism of second order, which acts on the institutional framing of the actors in order to incite processes of organisational learning. This mechanism should allow to order concrete communities in function of a common good, thereby orientating them towards generalising their interests to the largest possible community. Thus, on the level of scientific regulation, prospective evaluation methods have been developed since the seventies in order to meet the deadlocks of an evaluation of technologies based on an expert calculus of probabilities of risks or of indicators of social, cultural and environmental impact. According to E. Wenk, one of the founding fathers of technology assessment in the United States, the aim of those methods is to develop a truly prospective knowledge, which permits on the one hand to exercise our responsibility in 
anticipation of long term effects of technologies (cf. Wenk [39], p. 939) and to integrate, on the other hand, the dimension of uncertainty into the decision (cf. Wenk [39], p. 940). What is at stake in these institutional propositions is the necessity to give incentives in the direction of a learning process on the level of the dispositions specifically adapted to scientific and political actors in order to make them pursue, also in the future, a development of technologies that integrates the point of view of those excluded from the information society or of those subject to the risks of technological systems.

In the more specific domain of the Internet, this anticipative reflexivity of the institutional development of the sciences has given rise to the development of a more systematic knowledge of the social embedding of information technologies, as is the case in "social informatics" (Kling [15]). It has also stimulated the development of particular epistemic communities, linked to professional organisations as the IFIP (Berleur, Duquenoy and Whitehouse [7]) or an international organisation as the UNESCO (Unesco [36]). The development of such knowledge communities should allow to institute forms of co-regulation between institutional incentive structures and different self-regulated sectors of activity (Reidenberg [30], p. 10).

However, this second translation of the condition of increasing reflexivity also remains insufficient. Indeed, it is relying on already existing cooperative resources on the level of the life-world of the actors (J. Habermas [13] ; cf. also Maesschalck [22]) or on the level of cultural determinations of the potential community that define the selection criteria of the means to be allocated in the concrete realization of the engagement agreed upon 2 (Rorty [32] ; Lévy [20], cf. also Maesschalck [22]). Thus, this second way does not develop any reflexivity on the normative orientations of the actors, which leads to the re-evaluation of the cooperative orientations in function of the already acquired attitudes or cultural codes at work (Lenoble \& Maesschalck [19]).

Within the field of technology assessment (TA) this type of insufficiency can shed a new light on the relative weakness of institutions of TA in Europe. Even if this weakness is in part due to a certain fragmentation between a diversity of national and regional institutions, recent comparative research points to a more profound reason of this weakness. According to this research the main weakness that TA has to overcome is its current failure to acquire the confidence and the legitimacy of the political decision makers and in the same time, its incapacity to take into account a change in political culture, which next to representative democracy, favours direct

${ }_{2}$ One can also reconsider in this context the remarks of $\mathrm{R}$. Kling on the necessity of taking into account the financial cost of introducing computers into schools in order to sustain pedagogical innovation (Kling [16], p. 116) or on the question of the real beneficiaries of the increase in productivity in organisations through computerisation (Kling [16], p. 123). 
political participation of the citizens (Paschen H. \& Vig N.J. [27]). The proposed institutional framing, even if it's understood in the prospective sense of E. Wenk, is still linked to the expert culture that accompanied the emergence of TA in the seventies, and fails to take into account the political culture that characterizes parliamentary decision processes or citizens movements. In this perspective, an enforcement of the methods of TA in Europe will depend on their capacity to enable a more reflexive approach to its operational context. A tentative in that direction that could guide such a development is the Integrated Assessment Project of the United Nations Environmental Program (UNEP), which explicitly includes tools for capacity building of different actors participating in the assessment procedure (UNEP [35]).

From the point of view of the modified procedural approach to the regulation of socio-technical systems, one must thus take into account the demand for a joint increase in reflexivity within the deliberation on normative principles, by a common action on the actors and the institutions.

\section{APPLICATION OF THE REFLEXIVE APPROACH TO THE SELF-REGULATION OF THE INTERNET}

In his article on the self-regulation of the Internet, Eric Brousseau [9] proposes an original institutional solution, which meets both the incompleteness of solely technical means of self-regulation (standardisation or juridical self-rule) ([9], pp. 364-365; 368-369) and the inefficiency of coregulation in a classical sense ([9], pp. 370). Relying on the analysis of North [26], he introduces a principle of hierarchy within the conception of an institutional framework. Instead of a "common intervention based on the equity of the State, private corporations and interest groups in the procedures of regulation" (Brousseau [9], p. 370) - as is the case in coregulation in the classical sense - he proposes to consider a hierarchy between on the one hand, different private and specific institutional frameworks, which can elaborate "collective solutions of coordination", "adequate to a family of more specific cases" (Ibid.), and, on the other hand, a final instance of regulation that has to solve conflicts between the regulatory rules and the private norms.

Even though a purely juridical interpretation of this proposition is possible, the formulation of E. Brousseau clearly puts the emphasis on the importance of mechanisms which capacitate the reflexive resources. Indeed, as writes Brousseau, the mechanism of conflict resolution of the final 
instance attempts to "take into account the interests of the largest possible community" (p. 370). More precisely, this mechanism aims at maintaining the open character of the network, in order to avoid the misappropriation of self-regulation by particular interest groups. What is at stake in hierarchisation, is not so much the possibility to sanction, which would turn it into a sort of supra-national state, but rather the incentive relationship it establishes between co-regulation and multi-regulation. In fact, as Brousseau remarks, the multiple "virtual" communities already manifest a principle of openness in their mode of functioning. The user culture of those communities produces positive externalities which have implications beyond the interests of a particular community, such as allowing the diffusion of information of public interest or facilitating the possibility of citizens to develop certain services, etc. (p. 355).

However, this mechanism of openness can become inefficient when confronted with certain unprecedented ethical situations (e.g. how to forbid access to racist websites) or to certain monopolistic tendencies inherent to the management of the only scarcely available addresses and of the available transport capacity. That is why a final mechanism of conflict resolution is necessary in order to enforce and maintain the principle of openness within the network, which manifests itself already on the level of the multiregulation of different user communities.

The proposition of E. Brousseau can thus be summarized as a proposition of action on a double level: on the one hand, the favorisation of the proliferation of cooperative mechanisms based on the aggregative competences the actors (the so called 'user culture') in order to complete contractual agreements; on the other hand, the construction, also in a cooperative manner (of the type of alternative mechanisms of conflict resolution), of an authority of regulation of the common good. The reflexive nature of the formula appears on the level of constraints it implies in order to 'capacitate' this type of cooperative mechanisms. It has indeed to mobilize specific competences of the actors and to transform the mode of intervention of the institutional means of coordination.

One can further develop this proposition by applying it to the practical experience of ICANN (Internet Corporation for the Assignment of Names and Numbers) and other Internet regulatory bodies as the IETF (Internet Engineering Task Force) and the W3C (World Wide Web Consortium). First of all, in the case of ICANN, there is a clear will to attempt to take into account the reflexivity of the different type of actors in the decision process, as a means to guarantee a greater legitimacy of the decisions and a wider acceptance of its role by the Internet community. In that respect, one can consider the elections of October 2000 as an important test case. In this election five user representatives were designated by the worldwide ICANN 
membership through Internet voting. However, two evaluation reports, one from a ICANN study Committee [1] and one from an independent team of international research institutes [25], point to the same insufficiency of this process, which resides in its formal conception of the participation procedure. Both reports recommend the creation of institutional structures in order to enable the users to participate in the decision processes. In that sense "local and regional associations should be encouraged to self-organize (or catalysed by the Council) in order to provide global forums for discussion catering to particular language, culture or ideological groups" ([25], p. 6). The failure to go beyond a formal conception of participation and to take into account the necessity of a reflexive framing of the actors, has lead to a capture of the election process by the already well organized interest communities. As an example one can recall the mobilization of employees of the Japanese Internet corporations, in order to make them register as a member of ICANN and to vote for the candidates supported by the Japanese Business community. In a similar manner, the formal conception of participation in the Internet Society (ISOC), or the financial barriers to participation in the World Wide Web Consortium (W3C), does not allow to enable the reflexivity of different types of users which are affected by the evolution of the technical standardisation of the Internet.

\section{References}

[1] ALSC (2001), "Final Report on ICANN At-Large Membership", http://www.atlargestudy.org/final_report.shtml

[2] BECK U. (1995), Ecological Politics in an Age of Risk, translation by Amos Weisz, Polity Press, Cambridge.

[3] BECK U. (1997), The reinvention of politics : Rethinking Modernity in the Global Social Order, Polity Press, Cambridge.

[4] BENKLER Y. (2000), "From Consumers to Users, Shifting the Deeper Structures of Regulation Toward Sustainable Commons and User Access", in Federal Communications Law Journal, 52, pp. 561-579.

[5] BERLEUR J. (2000), "Ethique et autoroutes de l'information", in Rapports du Groupe CAPAS-CAWET, Académie Royale de Belgique, Bruxelles, 23 pp., http://www.kvab.be/Cawet/CawetInfor/FHbT.html.

[6] BERLEUR J. (2001), "Risk and Vulnerability of Democracy in Information Societies", in Report of the COMEST Sub-Commission on "The Ethics of the Information Society", UNESCO, 60 pp, pp. 40-54.

[7] BERLEUR J., DUQUENOY P. and WHITEHOUSE D. (eds.) (1999), Ethics and the Governance of the Internet, IFIP Framework for Ethics of Computing, Laxenburg, http://www.info.fundp.ac.be/ jbl/IFIP/cadresIFIP.html.

[8] BERLEUR J. and POULLET Y. (2001), "Quelles régulations pour l'Internet ?", manuscript proposed for publication.

[9] BROUSSEAU E. (2001), "Régulation de l'Internet : L'autorégulation nécessite-t-elle un cadre institutionnel ?", in Revue Economique, 52, numéro spécial sur l'Economie del'Internet, pp. 349-377, http://atom2.univ-paris1.fr/FR/membres/eric/eric.htm.

[10] DEDEURWAERDERE T. (2002a), "Biological Diversity Protection and Selfregulation of Local Communities: Some Implications of a Reflexive Institutionalist 
Approach", Conference Presented at the Workshop in Political Theory and Policy Analysis, Indiana University, Bloomington, http://dlc.dlib.indiana.edu/

[11] DEDEURWAERDERE T. (2002b), Action et contexte, Olms, Hidesheim/Zürich/NY.

[12] DEDEURWAERDERE T. and MAESSCHALCK M. (2001), "Autorégulation, éthique procédurale et gouvernance de la société de l'information", in Les Carnets du Centre de Philosophie du Droit, $\mathrm{n}^{\circ}$ 91, 24 pp. , www.cpdr.ucl.ac.be/cgi-bin/pub_membres.cgi.

[13] HABERMAS J. (1983), Moralbewusstsein und kommunikatives Handeln, Suhrkamp, Frankfurt a. M.

[14] HABERMAS J. (2000), Après l'Etat-nation, Une nouvelle constellation politique, trad. par R. Rochlitz, Fayard, Paris.

[15] KLING R. (ed.) (1996a), Computerization and Controversy, Value Conflicts and Social Choices, second edition, Academic Press, San Diego/New

York/Boston/London/Sydney/Tokyo/Toronto, pp. 108-132.

[16] KLING R. (1996b), "The Centrality of Organizations in the Computerization of Society", in KLING R. (ed.), Computerization and Controversy, Value Conflicts and Social Choices, second edition, Academic Press, San Diego, New York, Boston, London, Sydney, Tokyo, Toronto, pp. 108-132.

[17] KLING R. (1996c), "Beyond Outlaws, Hackers, and Pirates: Ethical Issues in the Work of Information and Computer Science Professionals, in KLING R. (ed.), Computerization and Controversy, Value Conflicts and Social Choices, second edition, Academic Press, San Diego, New York, Boston, London, Sydney, Tokyo, Toronto, pp. 848-869.

[18] LATOUR B. (1992). "Where Are the Missing Masses? The Sociology of a Few Mundane Artifacts" in BIJKER W. and LAW J. (eds), Shaping Technology/Building Society: Studies in Sociotechnical Change, MIT Press, Cambridge (MA), pp. 225-258.

[19] LENOBLE J. and MAESSCHALCK M. (2002), The Action of Norms, Kluwer International, London/New York, forthcoming.

[20] LEVY P. (1997), L'intelligence collective, Pour une anthropologie du cyberspace, La Découverte, Paris.

[21] MAESSCHALCK M. (1999a), "Réflexivité transcendantale et réflexivité opératoire, Développement d'un programme de recherche", in Les Carnets du Centre de Philosophie du Droit, $\mathrm{n}^{\circ}$ 84,1999,21p., www.cpdr.ucl.ac.be/cgibin/pub_membres.cgi.

[22] MAESSCHALCK M. (1999b), "Les limitations communautaires du jugement pratique, I. Communauté et jugement pratique chez Rorty et Habermas", in Les carnets du Centre de Philosophie du droit, $\mathrm{n}^{\circ} 77,28$ pp., www.cpdr.ucl.ac.be/cgi bin/pub_membres.cgi.

[23] MAESSCHALCK M. (2000), "Provenance et fondements de la pragmatique contextuelle", in Démocratie et Procéduralisation du droit, $\mathrm{Ph}$. Coppens et J. Lenoble (dir.), Bruylant, Bruxelles, pp. 97-124.

[24] MAESSCHALCK M. (2001), Normes et contextes, Les fondements d'une pragmatique contextuelle, Olms, Hildesheim/Zürich/New York, 324 pp.

[25] NAIS (2001), "ICANN, Legitimacy, and the Public Voice: Making Global Participation and Representation Work", report of the NGO and Academic ICANN study, http://www.naisproject.org/report/final/.

[26] NORTH D.C. (1990), Institutions, Institutional Change and Economic Performance, Cambridge University Press, Cambridge.

[27] PASCHEN H. \& VIG N.J. (2000), Parliaments and technology: the development of technology assessment in Europe, State University of New York Press, Albany (NY).

[28] POULLET Y. (2000), "Les diverses techniques de réglementation d'Internet : l'autorégulation et le rôle du droit étatique", in Revue Ubiquité, pp. 55-68.

[29] REIDENBERG J.R. (1998), "Lex Informatica: the Formulation of Information Policy Rules Through Technology”, in Texas Law Review, vol. 76, n³, pp. 553-584. 
[30] REIDENBERG J.R. (2001), "Protection de la vie privée et l'interdépendance du droit, de la technologie et de l'autorégulation", in Cahiers du C.R.I.D., vol. 19, forthcoming.

[31] RORTY R. (1982), Method, Social Science, Social Hope, in RORTY R. (ed.), Consequences of pragmatism, University of Minnesota Press, Minneapolis, 1982, pp. 191-210.

[32] RORTY R. (1997), "Universalisme moral et tri économique", trad. par G. Arnaud, in Futuribles, 223, pp. 29-38.

[33] SABEL C.F. (1993), "Constitutional Ordering in Historical Context", in F.W. Scharpf (ed.), Games in Hierarchies and Networks, Analytical and Empirical Approaches to the Study of Governance Institutions, Campus/Westview, Frankfurt a. M./Boulder (CO), pp.65-123.

[34] SUNSTEIN C. R. (2001), "The Daily We, Is the Internet Really a Blessing for Democracy?", in Boston Review, 26, pp. 4-9.

[35] UNEP (2001), Reference Manual for the Integrated Assessment of Trade-Related Policies, ETB Publications, New York / Geneva, http://www.unep.ch/etu/etp/acts/manpols/rmia.htm

[36] UNESCO, "Meeting of the Comest Sub-Commission on "The Ethics of the InformationSociety", Report (18-19 June 2001), 60 pp.

[37] VERBIEST Th. and WÉRY E. (2001), Le droit de l'Internet et de la société de l'information, Larcier, Bruxelles.

[38] VIVANT M. (1997), "Internet et modes de régulation", in Internet face au droit, Cahiers du CRID, $\mathrm{n}^{\circ} 12$, Bruxelles, Bruylant, pp. 215-230.

[39] WENK E., Jr. (1988), "New Principles for Engineering Ethics”, in KLING R. (ed.), Computerization and Controversy, Value Conflicts and Social Choices, second edition, Academic Press, San Diego, New York, Boston, London, Sydney, Tokyo, Toronto, pp. 932-944. 